\title{
Modelagem didática tridimensional de artrópodes, como método para ensino de ciências e biologia
}

Joallyson Gonçalves Beserra

Carlos Henrique de Brito

\section{Resumo}

Em meio à grande diversidade existente no Reino Animal, ofilo Arthropodaé o que possui a maior variedade de formas, conceitos e funções a serem estudadas e visualizadas. $O$ objetivo deste trabalho foi o desenvolvimento de modelos didáticos tridimensionais de artrópodes, acerca de caracteres morfológicos, visando um maior aprendizado do conteúdo teórico desenvolvido em sala de aula e a disponibilização de metodologias alternativas para o ensino de zoologia. $O$ trabalho foi desenvolvido em turmas de 70 ano do ensino fundamental e 20 ano do ensino médio com aulas teóricas e práticas intercaladas. Os resultados mostraram que a modelagem tridimensional é eficiente no ensino da morfologia de artrópodes por despertar o lado lúdico nos alunos sem dispersar o lado científico da atividade, auxiliando-os na aprendizagem e permitindo-os realizar a classificação dos grupos de artrópodes em seus táxons correspondentes.

Palavras-chave:artrópodes, modelagem, metodologias alternativas.

\begin{abstract}
On the great diversity in the animal kingdom, the arthropods have a huge variety of shapes, concepts and functions to be studied and visualized. The objective of this work was the development of didactic models of threedimensional arthropods, about morphological characters, designed to further learning of the theoretical content developed in the classroom and the availability of alternative methodologies for teaching zoology. The study was conducted in classes of $7^{\text {th }}$ and $2^{\text {nd }}$ year with theoretical and practical lessons interspersed. The results showed that the three-dimensional modeling is effective in teaching the morphology of arthropods to awaken the playful side in students without dispersing the scientific side of the activity, assisting them in learning and allowing them to perform the classification of groups of arthropod taxa in their corresponding .
\end{abstract}

Keywords: arthropods; modeling, methodology alternative. 


\section{Introdução}

A vastidão do mundo animal, com mais de 1.500 .000 espécies conhecidas, restringe os zoólogos a um ou alguns campos de estudo, tornando inviável aos pesquisadores estudar todos os grupos taxonômicos. Para tanto, cada grupo animal ou cada tipo de pesquisa exige o estudo de particularidades específicas para serem avaliadas e preservadas para futuras gerações.

O grande número de representantes animais conhecidos chega a ser surpreendente, mas fazendo-se a comparação da quantidade de artrópodes que compõem essa diversidade, pode-se observarque a maioria dos animais pertence aos artrópodes e, embora existam 1.101.289 espécies viventes descritas pertencentes a este táxon (Brusca, 2007), essa é apenas uma pequena porcentagem do número total de formas viventes, sendo que, as demais, ainda estão por serem descobertas. Alguns entomólogos acreditam que existem mais de 30 milhões de espécies de insetos (hexápodes) a serem determinadas (Rupppert, 2005). Além disso, existe um rico registro fóssil que se estende à porção mais antiga do Pré-Cambriano (Hickman, 2004).Há muito mais artrópodes que todas as outras espécies de metazoários em conjunto perfazendo cerca de $80 \%$ de todas as espécies animais conhecidas. Artrópodes comuns e familiares incluem aranhas, escorpiões, insetos, centopéias, caranguejos e camarões dentro de uma vasta gama de outros animais segmentados que apresentam exoesqueleto e apêndices articulados (Rupppert, 2005).

Considerando essa grande diversidade de espécies e uma grande diversidade de formas e funções, têm-se uma gama de estruturas a serem visualizadas. Isso traz à sala de aula uma enorme quantidade de termos e conceitos, o que gera problemas difíceis aos professores de Zoologia (Araújo-de-Almeida, 2007) que geralmente dispõem de pouco tempo para ensinar conteúdos tão complexos. Por isso, muitos alunos podem considerar desmotivante estudar conteúdos programáticos de zoologia em ciências (Oliveira, 2005).

É cada vez mais necessário o uso de inovações didáticas no ensino de Ciências e Biologia, tanto para alunos de Ensino Fundamental quanto do Ensino Médio. Essas inovações são consideradas um meio de buscar novas soluções para velhos problemas de ensino e aprendizagem. Tais soluções se concretizam como estratégias que buscam a interação dos alunos com a Ciência e com o tema tratado.

Na maioria das escolas há a escassez de material biológico e falta de estrutura laboratorial para realização de aulas práticas. Diante de algumas dificuldades observadas por alguns pesquisadores da área do ensino de Ciências e Biologia, materiais didático-pedagógicos alternativos (Kits)são utilizados por professores como forma de instrumentos auxiliares para a prática pedagógica. Tem sido observado, que a partir da utilização de materiais de baixo custo, facilmente adquiridos, é possível desenvolver aulas mais atraentes e motivadoras nas quais os alunos são envolvidos na construção de seu conhecimento (Souza et al., 2008) 
Estudos recentes têm aplicado novas metodologias didáticas baseados em construção de modelos tridimensionais de estruturas biológicas em sala de aula para uma melhor visualização e aprendizado acerca de estruturas morfológicas (Araújo-de-Almeida, 2007). Os modelos didáticos correspondem a um sistema figurativo que reproduz a realidade de forma especializada e concreta, tornando-a mais compreensível ao aluno (Justina, 2006), portanto a criação do modelo didático deve ser feita de maneira explicativa e a representar, com a máxima clareza, a realidade.

Baseado nisso, o presente trabalhodescreve a utilização de um novo método de ensino de morfologia dos artrópodes em escolas públicas de nível Fundamental e Médio. A metodologia desenvolvida buscou a maior interação dos alunos com os docentes, entre si e também com o material biológico, através de modelagens tridimensionais realizadas em grupo, baseados em animais fixados (conservados em via seca ou úmida mantidos em laboratório no setor de Biologia Animal) e em modelos desenvolvidos previamente em laboratório.

Mediante as dificuldades de fixação do conhecimento por alunos através de aulas teóricas, este trabalho teve como objetivo o desenvolvimento de modelos didáticos tridimensionais de artrópodes acerca de caracteres morfológicos, visando um maior aprendizado do conteúdo teórico desenvolvido em sala de aula. O trabalho objetivou ainda a disponibilização de metodologias alternativas para o ensino de zoologia nas instituições de ensino da região, fortalecendo a integração da universidade com a sociedade.

\section{Fundamentação Teórica}

O estudo de animais, pouco acessível à população e com termos não presentes no dia-adia dos alunos, acaba causando grande desmotivação na aprendizagem de zoologia em Ciências e Biologia. O tamanho diminuto de alguns exemplares, local de ocorrência ou o desconhecimento da importância ecológica e/ou econômica dos animais são fatores que tornam o aprendizado de Zoologia muito cansativo e desmotivante. Alguns autores concordam que quando a Zoologia é abordada de forma integrada com a Evolução, Ecologia, Educação Ambiental ou outras áreas (interdisciplinaridade) há um interesse maior dos alunos e com isso o ensino se torna mais dinâmico (Araujo-de-Almeida, 2007).

Trabalhos atuais apresentam novas metodologias de ensino que utilizam a construção, em sala de aula, de modelos tridimensionais de estruturas biológicas utilizando materiais recicláveis, massas de modelar, entre outros, para o ensino em diversas áreas da Biologia (Oliveira, 2005; Azevedo e Bezerra, 2006; Araujo-de-Almeida, 2007). Oliveira (2005) utilizou modelos tridimensionais para o ensino de Histologia aos alunos de Licenciatura em Ciências Biológicas da Unesp em Bauru - SP. Essa autora observou a dificuldade dos alunos em interpretar a correta posição das organelas celulares, com esse método, comenta, foi possível suprir a ausência de visão tridimensional das figuras dos livros didáticos. Já Azevedo e Bezerra (2006) 
utilizaram a construção de maquetes tridimensionais para o estudo do corpo humano na disciplina de Anatomia Humana do Curso de Graduação em Medicina do Centro de Ciências da Saúde da UFRN. Essa prática, além de servir como estratégia didática, veio a suprir a falta de corpos humanos para estudo.

Araujo-de-Almeida (2007) desenvolveu modelagens tridimensionais de animais e cladogramas auxiliando o ensino dos invertebrados anelídeos poliquetas aos alunos das disciplinas Biodiversidade I e III do Curso de Ciências Biológicas da UFRN. O trabalho dessa autora teve como objetivo proporcionar aos alunos uma melhor boa visualização das estruturas desses animais e uma melhor aprendizagem dos conceitos evolutivos envolvidos. Os poliquetas, como outros organismos invertebrados, são frágeis e de difícil acesso e quando conservados perdem suas características de coloração e morfológicas que desestimulam a aprendizagem, sendo, muitas vezes apenas vistos pelos estudantes através de fotos ou ilustrações.

Araujo-de-Almeida (2007), inicialmente, chamou a atenção dos alunos para as características morfológicas, histórias de vida, diversidade e importância ecológica e econômica desses animais através de fotos coloridas. Após estas explicações teóricas foram utilizados materiais recicláveis para a construção, pelos próprios alunos, de modelos tridimensionais que representassem as características principais dos organismos estudados. Além disso, como discute a autora, o uso de materiais recicláveis é de extrema importância para a reciclagem o que leva a uma conscientização ecológica de preservação do meio ambiente. Ao final de toda a construção das maquetes os alunos puderam verbalizar sobre as características morfológicas e evolutivas aprendidas. Salienta a autora que os alunos usaram de forma riquíssima a imaginação e criatividade, até mesmo recorrendo a elementos teatrais para tratar dos elementos morfológicos. Diversos trabalhos têm destacado a importância dos modelos didáticos, como facilitadores da compreensão dos estudos nas subáreas da Biologia (Giordan\& Vecchi, 1996; Brandão \& Acedo, 2000; Justina \&Ferla, 2006).

Em todas as citações anteriores os alunos foram graduandos em Biologia ou Medicina, sendo possível observar com esses relatos a importância de uma diferente metodologia de ensino. Dessa forma foi possível o uso dessa abordagem para alunos de Ensino Fundamental e Médio com a participação dos graduandos do curso de Licenciatura em Ciências Biológicas/CCA/UFPB, que coordenaram as atividades em sala de aula, na instituição pública de ensino. Essa proposta também auxiliou na formação de docentes na área de Ciências e Biologia com uma abordagem diferente do processo de ensino e aprendizagem, tornando-os veículos multiplicadores de novas idéias para o ensino. 


\section{Descrição metodológica}

As atividades foram desenvolvidas na Escola Estadual de Ensino Fundamental e Médio Ministro José Américo de Almeida na cidade de Areia - PB, que pertence à Rede Estadual de Ensino e é regida pela 3a Gerência Regional do Estado da Paraíba. O trabalho foi coordenado por aluno bolsista do PROLICEN (Programa de Licenciatura) do curso de Licenciatura em Ciências Biológicas/CCA/UFPB em turmas do 7ํㅡㄹ Ano do Ensino Fundamental e 2을 Ano do Ensino Médio nas disciplinas de Ciências e Biologia.

O trabalho inicial foi em laboratório com a revisão bibliográfica e a relação das principais classes de artrópodes e suas características mais significantes. A pesquisa levou em consideração, principalmente, os padrões de tagmose e a segmentação corpórea, com a utilização de livros especializados, espécimes conservados em laboratório ou animais vivos coletados, fotos, vídeos ou ilustrações coloridas encontradas na internet. Todo material da pesquisa foi utilizado para elaboração dos planos de aula.

De acordo com a revisão bibliográfica, pôde-se observar que o trabalho de modelagem aborda principalmente a classificação taxonômica a partir de caracteres morfológicos, assim, os artrópodes são o grupo perfeito para a atividade, já que toda sua classificação é feita a partir de tais características. Os padrões de tagmose e o tipo de segmentação corpórea são padrões que diferenciam as classes de artrópodes. Outras características importantes são a presença/ausência ou número de antenas, número de pernas e outros tipos de apêndices, tais como estruturas abdominais e número de segmentos entre outros. Além disso, tais estruturas apresentam grande variedade de formas e funções, tendo grande importância na caracterização dos diferentes tipos de artrópodes existentes (Galloet al., 2002).

Também, com base nos padrões corpóreos de segmentação e tipos e números de apêndice é possível compreender aspectos relacionados com a evolução e filogenia dos grupos. Com auxílio dos coordenadores, aulas foram preparadas para abordar teoricamente tais conceitos, mostrando não só as características morfológicas e fisiológicas, mas também aspectos ecológicos, econômicos e a diversidade dos grupos.

Depois dessa etapa, iniciou-se a confecção de algumas maquetes (modelos) que foram utilizadas como propostas estimuladoras da criatividade dos alunos. Os modelos foram feitos tendo como base na definição de modelo didático proposta por Justina et al. (2003). Descreve-se como modelo didático (Justina):

"...modelo didático corresponde a um sistema figurativo que reproduz a realidade de forma esquematizada e concreta, tornando-os mais compreensivel ao aluno. Representa uma estrutura que pode ser utilizada como referência, uma imagem que permite materializar a idéia ou o conceito, tornando-os assimiláveis. Os modelos didáticos devem simbolizar um conjunto 
de fatos, através de uma estrutura explicativa que possa ser confrontada com a realidade."(Justina et al., 2003 apud Rocha, 2010, p.16)

As aulas teóricas foram realizadas dependendo da disponibilidade de horários da escola, sempre no horário letivo e com a autorização prévia da administração escolar. Nessas aulas, foram apresentados aos alunos maquetes (modelos), fotografias, ilustrações, e material biológico mantido no Laboratório de Zoologia do CCA - UFPB, conservado em vias úmida e seca. Desta forma os alunos tiveram melhor consciência do tamanho, proporção, textura e tridimensionalidade de alguns artrópodes. Os aspectos da biologia, ecologia e importância desses grupos foram tratados, para estimular a curiosidade dos alunos.

Terminada a aula teórica, a próxima etapa foi auxiliar os alunos no desenvolvimento dos modelos tridimensionais. Foram utilizados materiais de baixo custo, tais como recicláveis (garrafas pet, restos de arame), massa de modelar infantil e biscuit, e na confecção dessas estruturas morfológicas, o tamanho dos espécimes não ultrapassou o tamanho real dos animais. As aulas práticas eram sempre realizadas após as aulas teóricas após os alunos terem uma boa noção do grupo com o qual trabalhariam a modelagem.

Nas turmas de 7ㅇ Ano, no total, onze aulas foram ministradas, sendo cinco teóricas, quatro práticas, uma aula para apresentação dos modelos desenvolvidos pelos alunos e uma aula para avaliação escrita. Nas turmas de 20 Ano foram dez aulas ministradas, sendo cinco teóricas, quatro práticas e uma aula para aplicação da avaliação escrita, não houve a apresentação dos modelos, que foi substituída pela participação dos alunos em uma feira de ciências sobre os artrópodes.

Os alunos de todas as turmas estiveram sob constante observação,e seu comportamento, participação e sua evolução no transcorrer das aulas foram objetos de avaliação. Os modelos didáticos dos alunos fora foram avaliados pelos professores da disciplina no que se refereoriginalidade e criatividade. No quesito apresentação (tanto em sala quanto na feira de ciências), além do aspecto visual dos modelos foi levada em consideração a desenvoltura oral dos estudantes no esclarecimento ao público.

\section{Resultados e discussão}

A Escola Estadual de Ensino Fundamental e Médio Ministro José Américo de Almeida

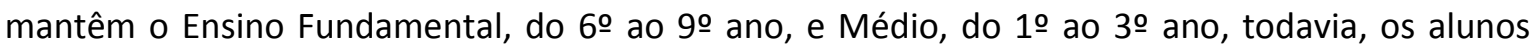

\footnotetext{
${ }^{1}$ JUSTINA L. A. D.; RIPPEL J. L.; BARRADAS C. M.; FERLA M. R. Modelos didáticos no ensino de Genética. In: Seminário de extensão da Unioeste, 3., 2003, Cascavel. Anais do Seminário de extensão da Unioeste. Cascavél; 2003. p.135 - 40.
} 
participantes deste trabalho foram apenas os devidamente matriculados no 70 Ano do Ensino Fundamental (Grupo I)e os matriculados no 20 Ano do Ensino Médio(Grupo II). O Grupo I constitui-se de três turmas ( $\mathrm{A}, \mathrm{B}$ e C), e totalizou 107 alunos dos quais 80\% (86 alunos) não obtiveram nenhuma ausência em quaisquer dos itens: a) aulas teóricas, b) aulas práticas, c) apresentação e d) avaliação. O Grupo II foi composto também por três turmas ( $A, B$ e C) totalizando 87 alunos dos quais 75\% (62 alunos) estiveram presente nos itens "a", "b", e "d" citados acima, já que no Grupo II não houve apresentação em sala de aula, atividade substituída por uma feira de ciências. Os Grupos foram compostos pelo 2으 Ano Médio e 7ํㅡ Ano Fundamental, por apresentarem em seu plano curricular obrigatório o módulo Zoologia, estudando a diversidade dos animais, o que permitiu o desenvolvimento do presente trabalho.

\subsection{Ensino Fundamental (Grupo I)}

As turmas A e B do 70 ano apresentavam alunos com faixa etária entre 12 e 14 anos e a turma C, era composta por alunos repetentes e com idade superior a 15 anos.

No total, onze aulas foram ministradas, sendo cinco teóricas, quatro práticas, uma aula para apresentação dos modelos desenvolvidos pelos alunos e uma aula para avaliação escrita. A apresentação e a avaliação formaram duas das três notas correspondentes ao 3 o bimestre escolar dos alunos. As aulas teóricas (Figura 1) foram ministradas com o auxílio de um retroprojetor. As transparências foram preparadas com "layout" paisagem como slides de apresentação Power Point. Em cada folha de transparência foram impressos dois slides para que pudessem ser bem ampliados na projeção.

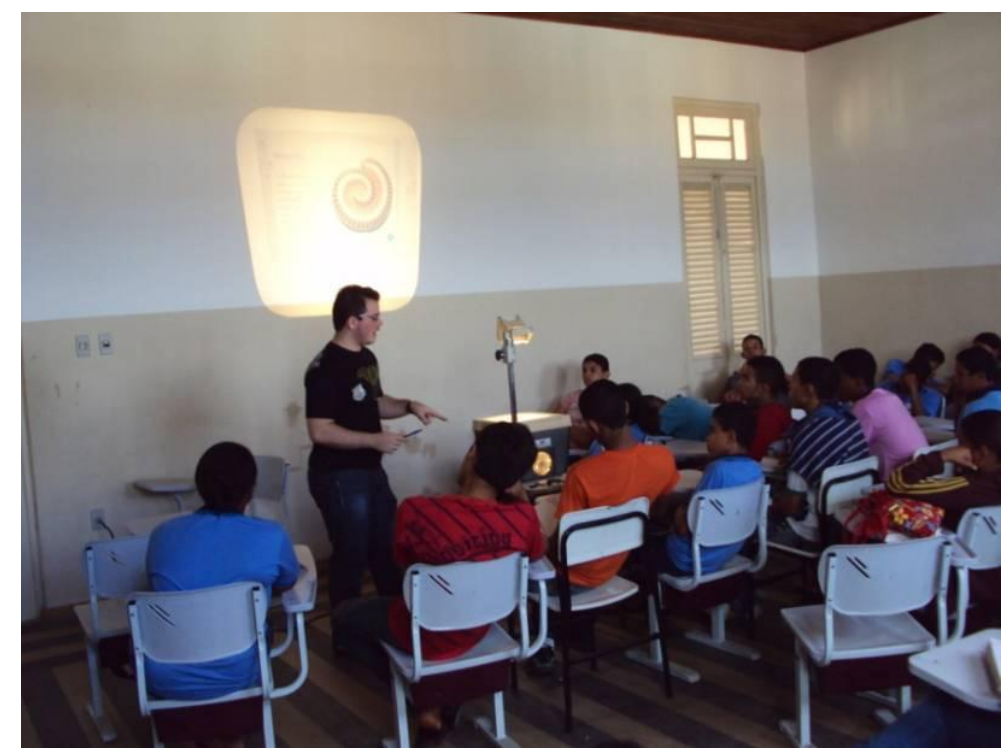

Figura 1 - Aula Teórica Ministrada com auxílio de retroprojetor. 
A primeira aula, uma explanação geral sobre artrópodes, evidenciou as semelhanças entre esses animais que os fazem ser parte de um mesmo grupo. Além dessas características, a aula trouxe em seu conteúdo as classes dos Arthropoda para que os alunos pudessem tomar conhecimento da diversidade do grupo com o qual iam trabalhar.

Como o interesse lúdico do trabalho só seria instigado nas aulas práticas,a diversidade dos artrópodes apresentou-se como uma solução para o interesse dos alunosnas aulas teóricas ministradas.Ao lado dos tópicos de cada transparência utilizada nas aulas teóricas, a imagem de um representante animal "curioso" foi fixada, despertando curiosidade acerca da figura e instituindo o debate e o despertar do interesse nos artrópodes. Imagens, tais como, de um Macrocheirakaempferi(maior artrópode conhecido) ao lado de um homem, de tarântulas Cromatopelmacyaneopubescens(que possuem uma coloração peculiar), escorpiões-vinagre e amblipigídeos (acaracnídeos bastante incomuns), dentre outras, foram utilizadas. As imagens também foram utilizadas para demonstrar estruturas corpóreas e conceitos, tais como, segmentação e tagmatização. A partir deste momento pôde-se comentar sobre os artrópodescom o uso de uma linguagem mais científica eutilizando palavras como tagmas, segmentos, apêndices e táxons. Nesse aspecto, se evidenciou que uma aula introdutória é fundamental para o bom andamento do trabalho.

$\mathrm{Na}$ terceira aula, a primeira aula de modelagem, a turma se dividiu em equipes de no máximo quatro alunos. As equipes sempre foram mantidas iguais em todas as aulas teóricas, para um entrosamento gradual no desenvolvimento do trabalho e para que os alunos mais próximos pudessem combinar sobre o material que levariam à sala de aula para montar seus modelos. Assim, foi levado à sala de aula o modelo didático preparado em laboratório pelo bolsista, e antes da montagem dos modelos didáticos pelos alunos, foi revisado o conteúdo da aula anterior dando ênfase a morfologia externa do animal. Nessas aulas práticas, animais conservados em via úmida e/ou seca, também foram utilizados para confecção dos modelos didáticos (Figura 2).

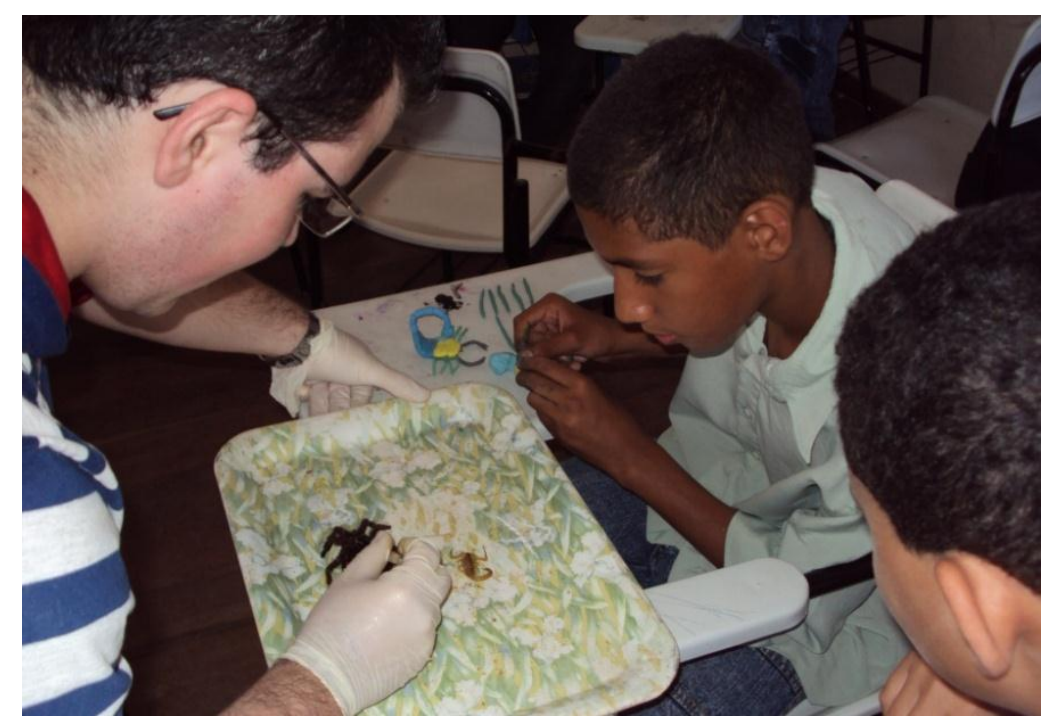

Figura 2 - Montagem dos modelos didáticos pelos alunos. 
De cada táxon foram produzidos dois modelos didáticos em laboratório, para os insetos, uma formiga (Figura 3) e uma joaninha. Todos os modelos didáticos foram produzidos com massa do tipo "biscuit" e coloridos com tinta guache (a tinta foi misturada à massa), sendo que cada tagma foi modelado com uma cor (Figura 3) para melhor diferenciação morfológica. Antenas, algumas patas e quelíceras eram representadas por fios elétricos. Os modelos didáticos serviram para incitar a criatividade dos alunos mostrando como deveriam montar os seus próprios modelos, baseados nas aulas teóricas e nos animais conservados em via úmida e seca.

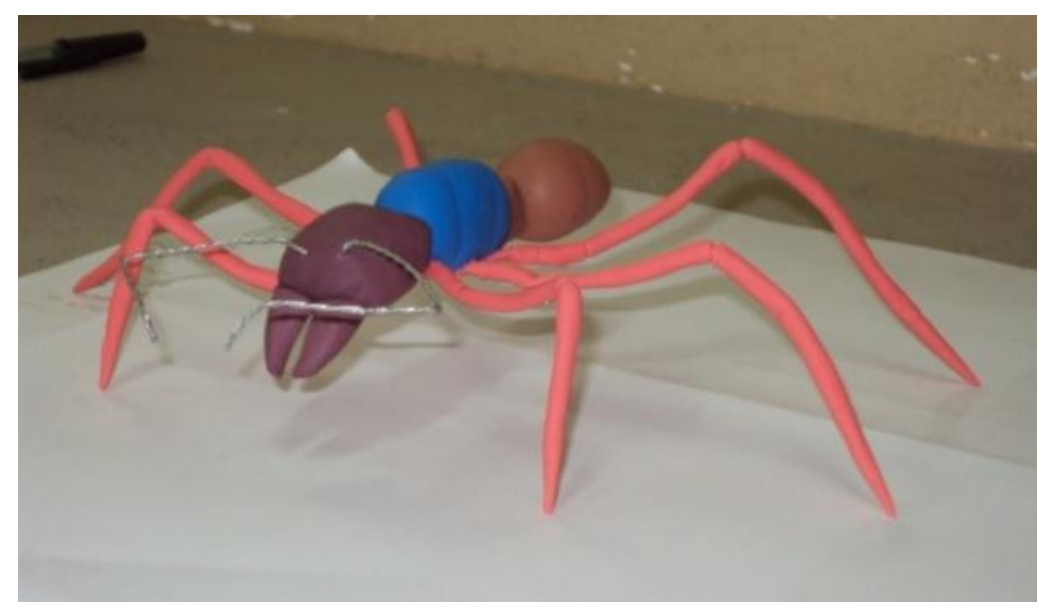

Figura 3. Modelo didático de inseto preparado em laboratório.

As aulas subsequentes seguiram a mesma distribuição, sempre uma teórica sobre o táxon - para poder conhecer bem os conceitos e morfologia da classe;- e posteriormente a modelagem correspondente ao grupo estudado. Assim foi, a partir dos insetos, com os crustáceos, aracnídeos e por fim, com os Myriapoda. Os modelos didáticos (Apêndices - A1) foram caranguejo e camarão para os crustáceos; escorpião e caranguejeira para aracnídeos; e embuá e lacraia para os myriapoda. Buscou-se sempre os representantes mais conhecidos para facilitar a modelagem aos alunos. Todos os modelos foram criados levando em consideração todos os detalhes de sua morfologia (Rupppert, 2005).Ao contrário dos modelos, que procuraram ser o mais comuns possíveis, os animais levados à sala de aula conservados em via seca ou úmida foram os mais incomuns disponíveis no laboratório, isso leva os alunos à se interessarem ainda mais. Foi observado que quanto maior o animal, maior o interesse e a curiosidade dos alunos. Por exemplo, com lagostas e tarântulas, os alunos ficavam mais interessados em saber quais as funcionalidades das estruturas corporais, diferente de uma formiga, às quais já estão habituados a ver todos os dias.

Foram confeccionados 92 modelos nas três turmas do Grupo I, 23 de cada táxon, representando insetos, crustáceos, aracnídeos e myriapoda. Dentre os materiais utilizados observou-se que a massa de "biscuit" é a mais adequada para a confecção dos modelos por 
apresentar durabilidade e dureza, podendo ser manuseada por várias vezes sem deformar-se. Os modelos confeccionados com massa de modelar tanto em sala de aula como em laboratório não se mostraram adequados, pois com o manuseio perderam a forma facilmente e não conseguiram ficar fixos, já que os artrópodes são formados por tagmas e apêndices e a massa de modelar não consegue dar sustentabilidade às ligações.

A participação dos alunos permitiu a interação positiva com a metodologia aplicada, apresentando-se curiosos e participativos em aulas teóricas e práticas. No que se refere ao ensino de artrópodes, a utilização de modelos didáticos é bastante relevante, pois permite construir o conhecimento sobre o objeto ao invés de apenas transformar o aluno num receptor de informações teóricas. Além disso, a diversidade de material pedagógico facilita o aprendizado tornando as aulas práticas mais dinâmicas e produtivas.

A apresentação dos modelos montados pelos alunos foi realizada na $10^{0}$ aula, onde cada membro da equipe ficou reponsável por apresentar um dos modelos didáticos. Os alunos tinham como objetivo mostrar a morfologia externa de cada modelo mostrando quais características evidenciavam que o animal pertencia à classe correspondente. $\mathrm{O}$ resultado deste projeto foi observado nas notas adquiridas pelos alunos nas avaliações escritas, que abordou desde os conceitos de segmentação e tagmatização até as características de cada classe de artrópodes.

As turmas A, B e C, foram avaliados indistintamente. A turma A e B (12 a 14 anos, não repetentes) obtiveram uma média de 8,1 e 7,6 respectivamente, na prova escrita, enquanto a média da turma C (15 anos ou mais e repetentes) foi de 5,8. A apresentação oral, onde os alunos puderam expressar seu conhecimento de forma livre, teve as médias de 8,9; 8,6 e 9,9 nas turmas A, B e C, respectivamente (Figura 4). Pôde-se observar que os alunos da turma C, obtiveram maior média na apresentação oral, evidenciando que a avaliação escrita nem sempre deve ser o único caminho de avaliar os conhecimentos adquiridos pelos alunos.

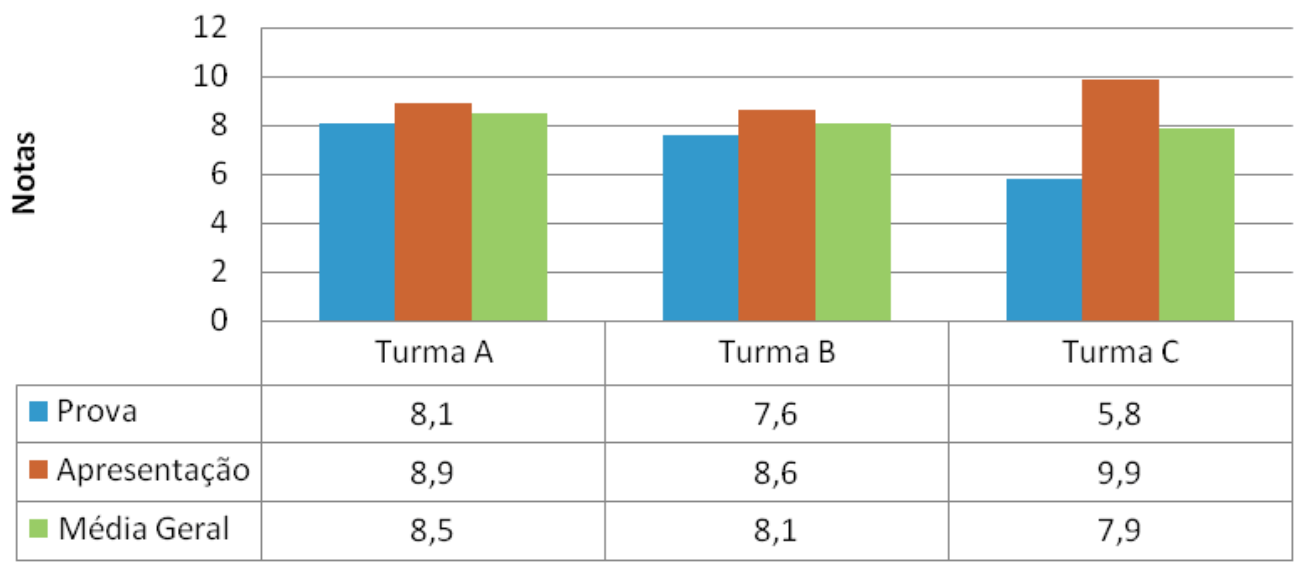

Figura 4. Médias das provas escritas, apresentações orais e médias gerais das turmas $A, B$ e $C$ do 7o Ano do Ensino Fundamental da Escola Estadual de Ensino Fundamental e Médio Ministro José Américo de Almeida. 
Segundo Shepardson (2002), as crianças indicam como insetos as borboletas e as aranhas. Associam esses animais com habitat abaixo do solo, com plantas, abaixo de troncos e pedras, e outros habitats característicos. Os alunos do 70 Ano não tinham conhecimento prévio algum sobre os artrópodes, logo,myriapodas e aracnídeos também eram considerados insetos por eles. Houve o caso de alunos citarem lagartixas como insetos. Em relação à classificação taxonômica dos animais, a maioria das crianças classifica os animais de acordo com o habitat e locomoção (Kattmann, 2001). Com as aulas finalizadas observou-se que o método aplicado aos alunos corrigiu as deficiências em relação à taxonomia básica dos artrópodes.

O trabalho foi bem aceito e aprovado pelos professores titulares da disciplina, pela diretoria da instituição e todos os alunos que tomaram conhecimento do que estava a ser desenvolvido no 7 음 ano.

Três meses após o término de todas as aulas teóricas e práticas, um questionário(Apêndice - A2) foi aplicado aos alunos do Grupo I com o objetivo de avaliar o conhecimento adquirido a metodologia desenvolvida, em quais aspectos contribuiu e como poderia melhorar. O questionário aplicado foi composto por sete questões subjetivas, que abordaram o conhecimento sobre artrópodes, o suporte que a disciplina de ciências fornece aos discentes e como a modelagem ajudou na formação do conhecimento dos alunos.

Como dito, os alunos não tinham conhecimento prévio sobre os artrópodes. Com o questionário, confirmou-se a hipótese. Quando questionados “Onde conheceu os artrópodes? Onde aprendeu sobre eles?" as respostas foram predominantemente "na escola" (Figura 5) enquanto alguns poucos responderam que já os tinham conhecido em casa com os pais, ou no pátio daescola com amigos

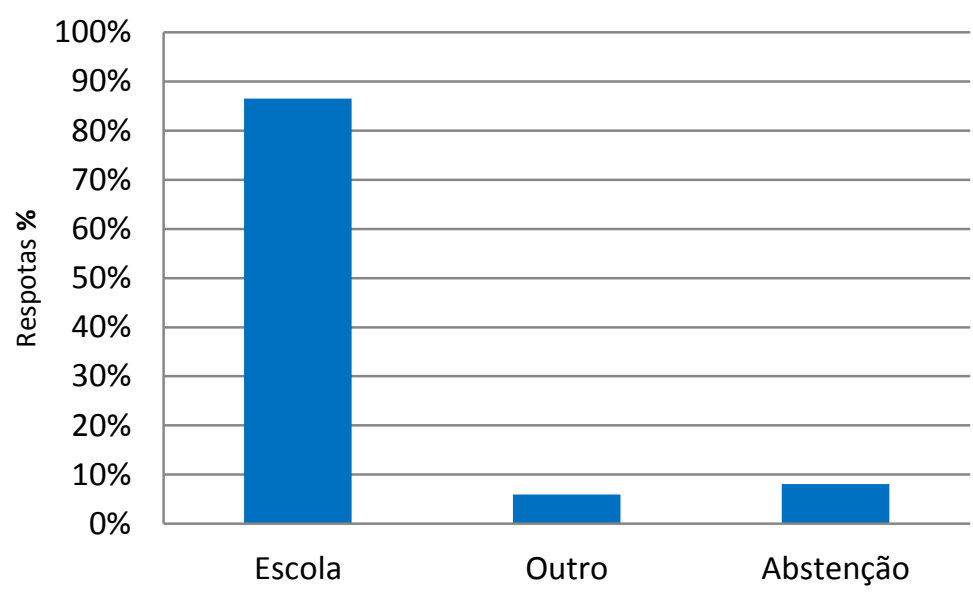

Figura 5. Respostas dos alunos do 70 Ano (Grupo I). Primeiro contato com os artópodes 
Quanto ao conceito e importância dos artrópodes obteve-se um alto índice de abstenção às perguntas, o que não ocorreu em relação à taxonomia. A modelagem tridimensional objetivou principalmente a diferenciação taxonômica das classes desse filo, o questionário pós-projeto mostrou que o conhecimento sobre artrópodes persistente foi aquele ao qual a metodologia alternativa mais se dedicou, enquanto padrões conceituais e teóricos não foram tão bem relembrados pelos alunos, como mostra a figura 6 .

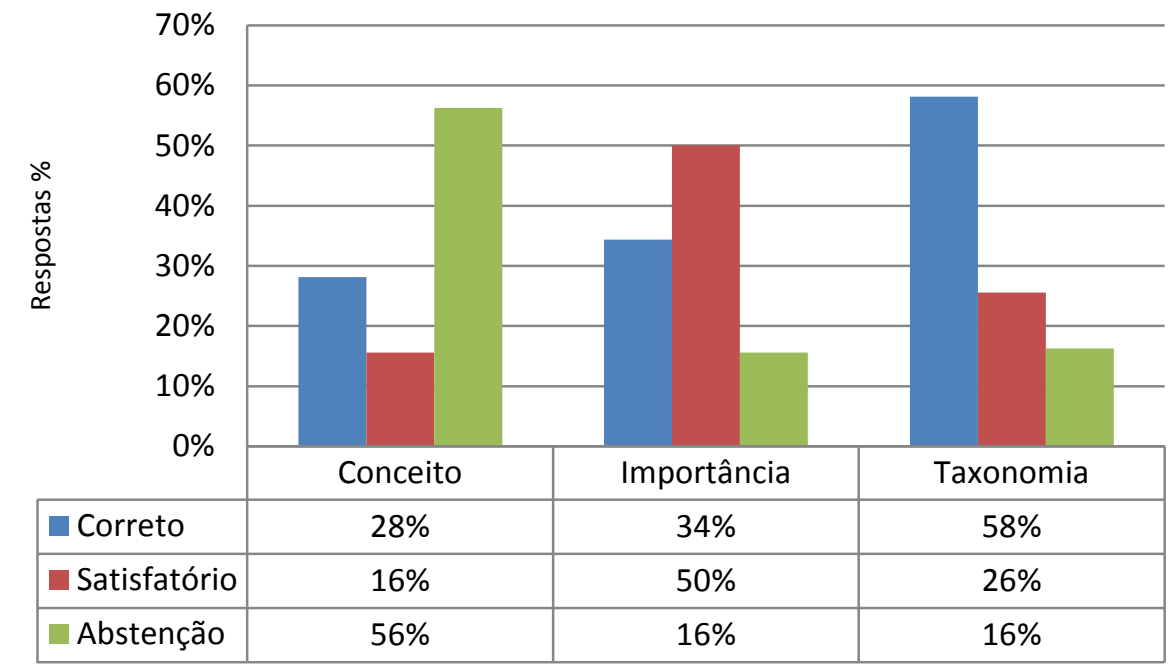

Figura 6. Respostas dos alunos do 7ํ Ano (Grupo I). Conhecimento sobre artrópodes.

Todos os alunos que conseguiram diferenciar taxonomicamente os artrópodes citaram características morfológicas: número de patas, divisão corporal e quantidade de antenas. Essa foi uma abordagem bem mais técnica e científica do que as classificações ideológicas aplicadas pelos alunos antes do projeto, como habitat, alimentação ou locomoção.

Abordados acerca do que deveria melhorar no ensino de artrópodes, os alunos aprovaram a metodologia aplicada e afirmaram que não há o que mudar (Figura 7).

Algumas respostas vieram em forma de sugestãosobre as aulas. Dentre as observações feitas pelos alunos como respostas ao questionário estavam:

- Levar os artrópodes vivos à sala de aula para um contato com os alunos;

- Um pequeno laboratório para se desenvolver as aulas práticas;

- Equipamentos para as aulas, como luvas e pinças para manuseio disponível para todos os alunos. 


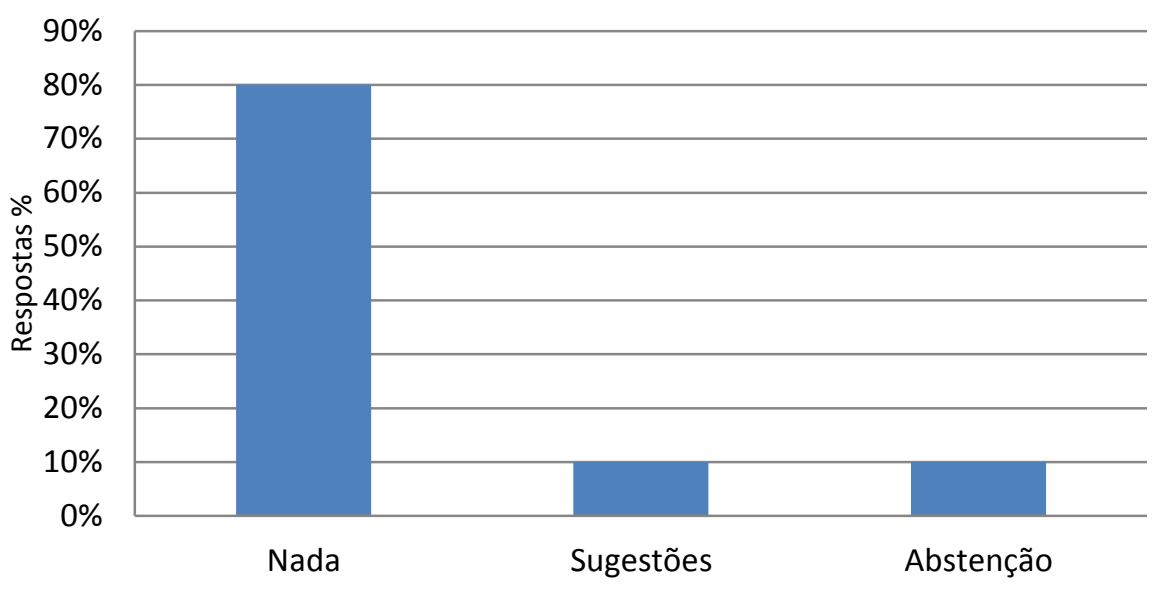

Figura 7. Respostas dos alunos do 70 Ano (Grupo I). Mudanças que devem ocorrer no ensino de artrópodes.

A última pergunta do questionário foi como a modelagem ajudou os alunos no aprendizado sobre artrópodes, grande parte, afirmou que a modelagem melhorou na visualização das patas, antenas, divisão do corpo e na diferenciação das classes, ou seja, grande parte dos alunos certificou que sob algum aspecto de visualização morfológica a modelagem contribuiu. Outrosalunos citaram a palavra criatividade, expressando o quão a modelagem estimulo-a em sala de aula (Figura 8).

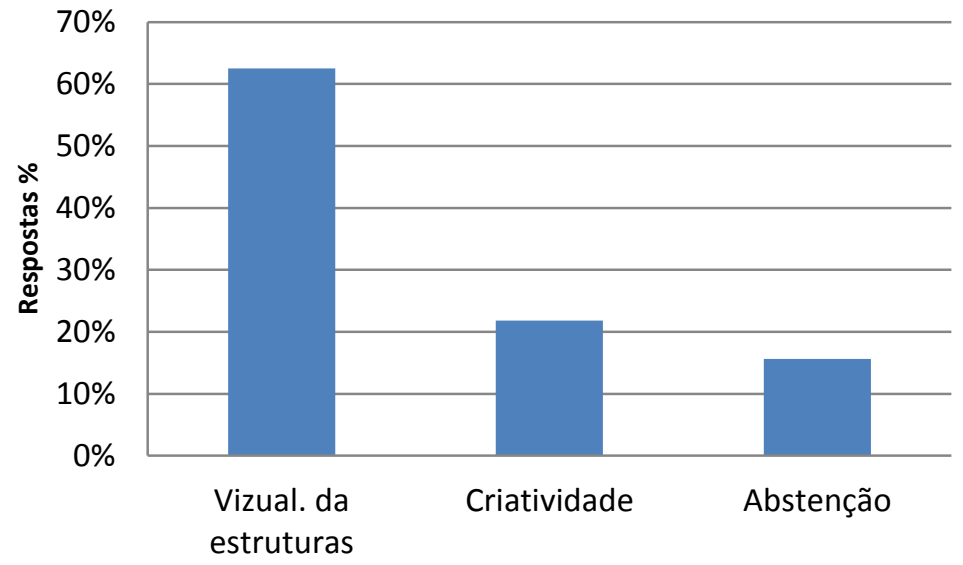

Figura 8. Respostas dos alunos do 7o Ano (Grupo I). Contribuição da modelagem de artrópodes no aprendizado.

Observou-se que depois dos três meses de trabalho desenvolvido a metodologia aplicada foi relembrada como uma atividade prazerosa que poderia ser desenvolvida outra vez. É impossível não citar no presente trabalho o quão impressionante foi observar o envolvimento dos 
alunos com a metodologia, bem como o nível de conhecimento técnico e científico que os alunos adquiriram sobre os artrópodes.

\subsection{Ensino Médio (Grupo II)}

Durante a segunda etapa do projeto,foi aplicada a mesma metodologia utilizada no Grupo I.Esse grupo era composto por turmas de 20 Ano do Ensino Médio. No total, 10 aulas foram ministradas, sendo cinco teóricas, quatro práticas e uma aula para aplicação da avaliação escrita. As aulas teóricas foram ministradas com o auxílio de um retroprojetor, enquanto nas práticas, os alunos dividiram-se em equipes de quatro componentes. As aulas tanto teóricas como práticas foram aplicadas da mesma forma e com a mesma metodologia que as lecionadas no Grupo I.

As aulas teóricas do Grupo II tiveram a mesma base das aulas preparadas para o ensino fundamental, todavia, contendo conceitos adicionais acerca das características fisiológicas de cada táxon. Após cada aula teórica, da mesma forma que no Ensino Fundamental, os alunos foram organizados em grupos de quatro para que pudessem construir os modelos tridimensionais. Ao fim da última aula teórica foi entregue aos alunos uma tabela elaborada pelo bolsista para auxiliar na avaliação escrita. Os alunos desse grupo estavam sendo preparados para o PSS (Processo Seletivo Seriado) da UFPB bem como para o ENEM (Exame Nacional do Ensino Médio). Ambos os exames são compostos por questões de múltipla escolha, por isso, a avaliação aplicada consistiu de 14 questões de múltipla escolha abordando todo o conteúdo ministrado em sala de aula.

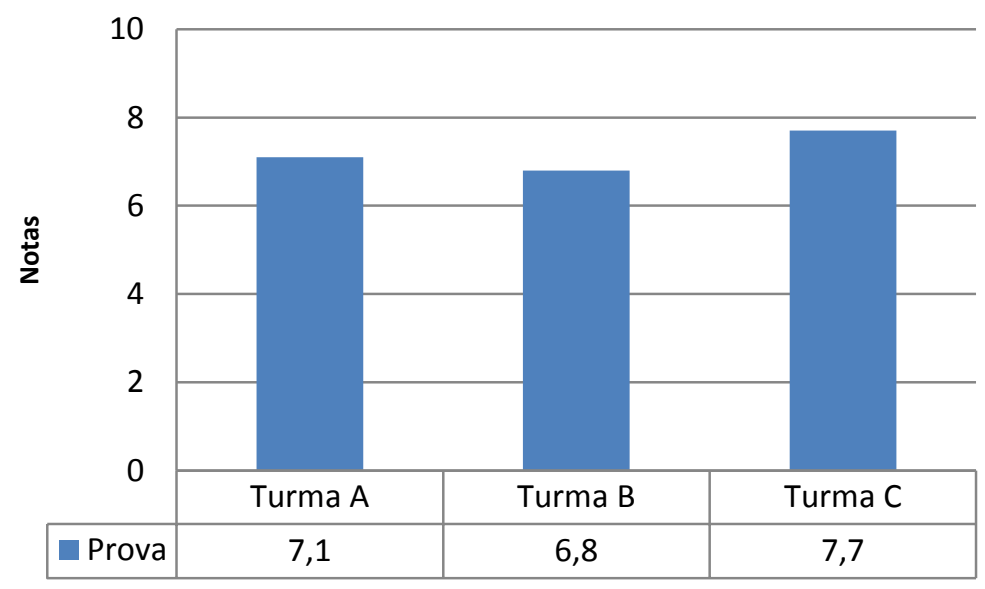

Figura 9. Médias das provas escritas das turmas $A, B$ e $C$ do $2^{\circ}$ Ano do

Ensino Fundamental da Escola Estadual de Ensino Fundamental e Médio

Ministro José Américo de Almeida.

O desempenho dos alunos do Grupo II(Figura 9) esteve abaixo do Grupo I, e apesar de participativos, os alunos não se mostraram tão interessados na modelagem como os alunos do 70 
Ano, haja vista que o presente grupo é composto por jovens e adultos os quais não interagem de maneira tão lúdica com a metodologia, diferentemente dos adolescentes avaliados no Grupo I.

Ao final do projeto os modelos didáticos foram utilizados para exposição na Feira de Ciências anual, organizado pela escola. Na oportunidade foram selecionados quatro alunos do ensino médio para apresentar os modelos didáticos construídos, bem como apresentação geral do projeto (Figura 10).

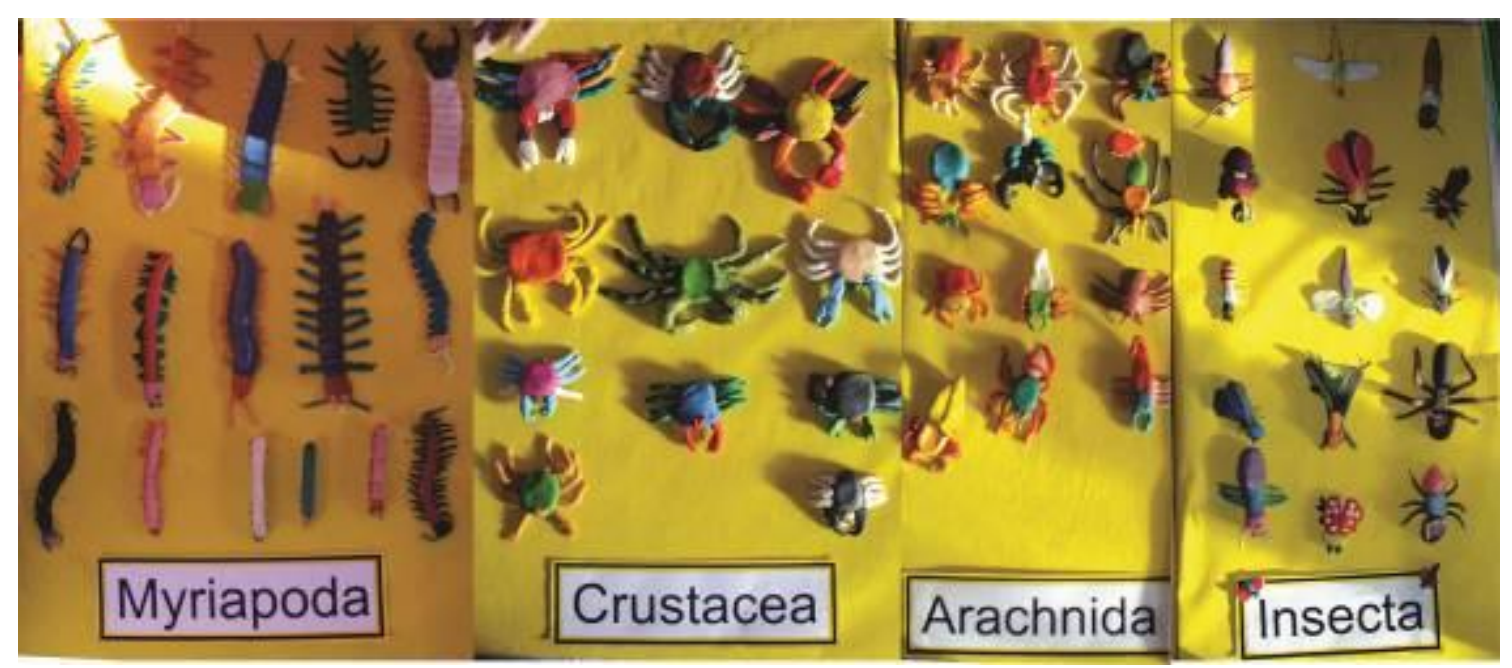

Figura 10. Modelos didáticos preparados pelos alunos do 2ำ Ano Médio apresentação na Feira de Ciências da E.E.E.F.M. Ministro José Américo de Almeida.

\section{Considerações finais}

A partir dos resultados obtidos, conclui-se que o trabalho ajudou não somente no aprendizado individual do aluno, mas na troca de conhecimento entre alunos da mesma equipe e com equipes da mesma turma, gerando dúvidas e discussões que resultaram num crescimento coletivo. Tendo como instrumento a discussão, os alunos desenvolveram o senso crítico individual, sendo isso, um bom mérito para a formação científica e pessoal.

Essas metodologias alternativas têm a capacidade de despertar o lado lúdico nos alunos sem dispersar o lado científico da atividade (Beserra, 2010), mostrando o quanto são eficientes. A confecção dos modelos didáticos capacitou os alunos a reconhecer e classificar os diversos táxons presentes dentro dos artrópodes. Além disso, a modelagem proporciona aos alunos o despertar de um lado lúdico e atrativo, podendo ser desenvolvida em qualquer nível de ensino do infantil ao superior, utilizando os modelos não só nas aulas de sua construção, mas em análises morfológicas posteriores, em oficinas ou feiras científicas. 
A utilização de modelos didáticos tridimensionais é uma alternativa que deve ser estimulada nos estabelecimentos de ensino, pois promove a relação do conteúdo estudado com aulas práticas, onde os alunos podem observar e aplicar os termos e conceitos conhecidos em sala de aula, tornando o conteúdo mais assimilável e compreensível.

A modelagem pode e deve ser sim aplicada; e não só fazendo alusão ao ensino de artrópodes, mas em outras diversas matérias curriculares, pois a modelagem didática pode ser desenvolvida de modo aceitável em quaisquer análises morfológicas, seja de células, órgãos, sistemas ou organismos, não só no ensino de Ciências e Biologia, mas também em Geografia, Física e Matemática.

\section{Referências}

ARAUJO-DE- ALMEIDA, E. Modelagem de cladogramas tridimensionais e aprendizagem de conceitos em Sistemática Filogenética. In: Anais do IV Colóquio Nacional em Epistemologia das Ciencias da Educação. Natal: IV CNECE, 2007.

AZEVEDO, G. D.; BEZERRA, M. J. D. avaliação da aprendizagem: uma estratégia inovadora na disciplina de Anatomia Humana. In: GOMES, M. C. S. (org). Tecendo saberes e compartilhando experiências sobre avaliação. Natal: Ed. UFRN, 2006.

BESERRA, J. G. BRITO, C. H. Modelagem didática tridimensional de artrópodes, como método para o ensino de ciências.ENCONTRO DE INNICIAÇÂO À DOCÊNCIA, 13, 2010, Bananeiras. Anais eletrônicos... João Pessoa: UFPB, 2010. Disponível em: http://www.prac.ufpb.br/anais/XIIENEX_XIIIENID/ENID/Prolicen/Completos/4/4CCADCBPL01.doc. BRANDÃO, R. L.; ACEDO, M. P. D. Modelos didáticos em genética: a regulação da expressão do Operon de lactose em bactérias. Genetics and Moleculary Biology, v. 23, n. 3, 2000, p. 179.

BRUSCA, R. C.; BRUSCA, G. J. Invertebrados. 2ed.Rio de Janeiro: Guanabara Koogan 2007.

GALLO, D. et al. Manual de Entomologia Agrícola. São Paulo: Agronômica Ceres, 2002. 531p.

GIORDAN A.; VECCHI, G. Do saber: das concepções dos aprendentes aos conceitos científicos. $2^{a}$ Ed. Porto Alegre: Artmed, 1996, 222p.

HICKMAN, C. P.; ROBERTS, L. S.; LARSON, A. Princípios integrados de zoologia. Rio de Janeiro: Guanabara Koogan, 2004.

JUSTINA L. A. D.; RIPPEL J. L.; BARRADAS C. M.; FERLA M. R. Modelos didáticos no ensino de Genética. In: Seminário de extensão da Unioeste, 3., 2003, Cascavel. Anais do Seminário de extensão da Unioeste. Cascavél; 2003. p.135 - 40 apud ROCHA A. R.; MELLO W. N.; BURITY C. H. F. A utilização de modelos didáticos no Ensino Médio: Uma abordagem em artrópodes. Saúde e ambiente em revista, Duque de Caxias, v. 5, n. 1, p.15-20, jan./jun. 2010. Disponível em: 
<http://publicacoes.unigranrio.edu.br/index.php/sare/article/viewFile/1041/683> . Acesso em: 22 mai. 2011.

JUSTINA L. A. D.; RIPPEL J. L.; BARRADAS C. M.; FERLA M. R. Modelos didáticos no ensino de Genética. In: Seminário de extensão da Unioeste, 3., 2003, Cascavel. Anais do Seminário de extensão da Unioeste. Cascavél; 2003. p.135 - 40.

JUSTINA, L. A. D.; FERLA, M. R. A utilização de modelos didáticos no ensino de genética - exemplo de representação de compactação do DNA eucarioto. Arquivo Mudi, v. 10, n. 2, 2006, p. 35 - 40.

KATTMAN, U.; Aquatics, Flyers, Creepers and Terrestrials - students' conceptions of animal classification.Journal of Biological Education. 35 (3). 2001.

OLIVEIRA, S. S. Concepções alternativas de ensino de Biologia: como utilizar estratégias diferenciadas na formação inicial de licenciados. Educar. v. 26, p. 233-250, 2005.

RUPPERT, E. E; FOX, R. S.; BARNES, R. D. Zoologia dos Invertebrados. 7. ed. São Paulo: Roca, 2005. $1168 p$.

SHEPARDSON, D. Bugs, butterflies, and spiders: children's understandings about insects.Int. J. Sci. Educ., Vol. 24, N. 6, 627-643. 2002.

SOUZA, D. C.; ANDRADE, G. L. P.; NASCIMENTO JUNIOR, A. F. Produção de material didáticopedagógico alternativo para o ensino do conceito pirâmide ecológica: um subsídio a educação científica e ambiental. In: Fórum Ambiental da Alta Paulista. 4., 2008, São Paulo. Anais... São Paulo: ANAP, 2008. cd-rom. 


\section{Apêndices}
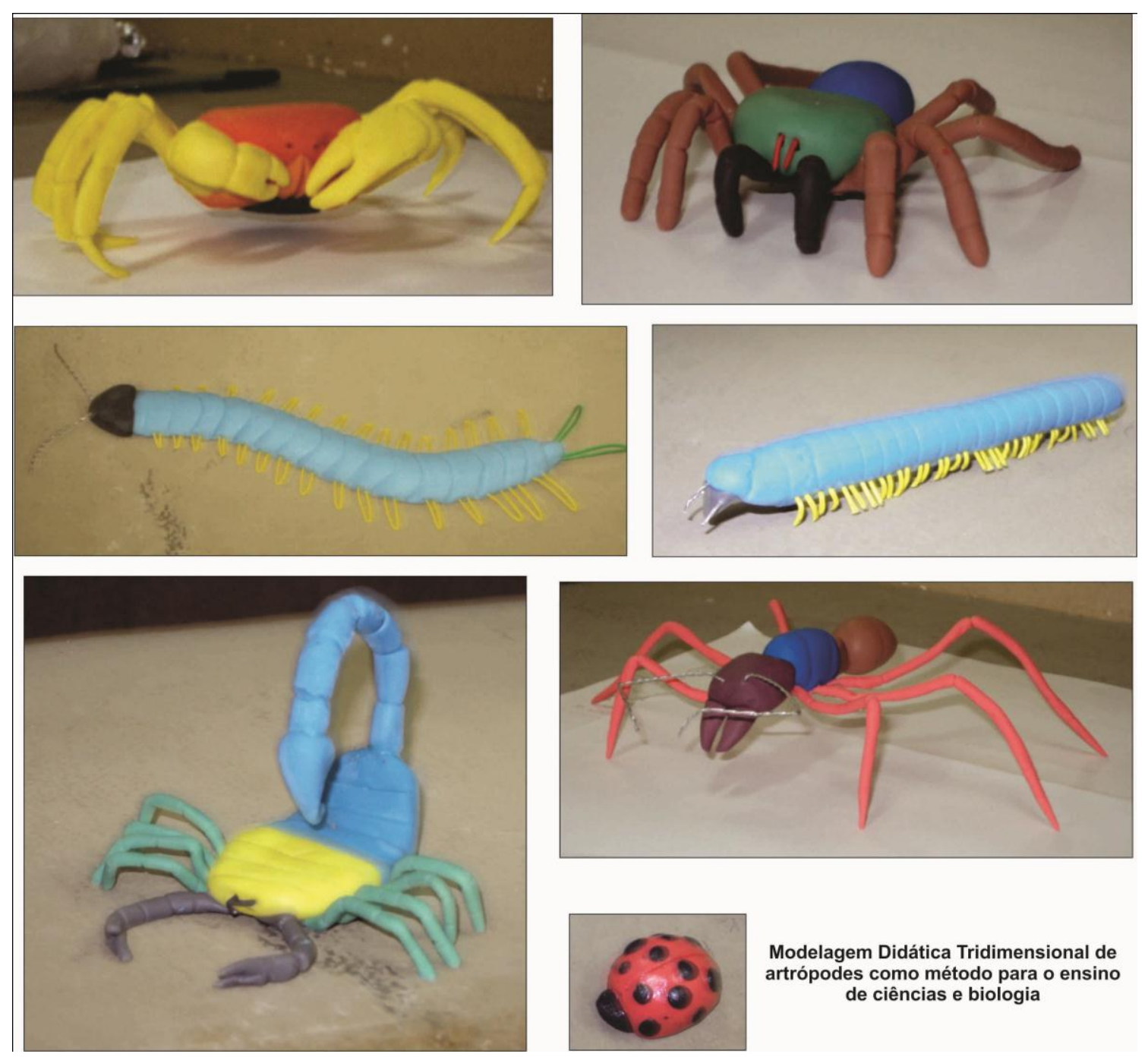

Modelagem Didática Tridimensional de artrópodes como método para o ensino de ciências e biologia

Figura A1 - Modelos didáticos tridimensionais de artrópodes preparados em laboratório 
Projeto de Ensino: Modelagem didática tridimensional de artrópodes, como método para o ensino de ciências e biologia

\section{Questionário aos alunos:}

1. O que são artrópodes? Você conhece algum? Se conhecer, cite alguns.

2. Em sua opinião qual a importância destes para o ser humano?

3. Onde você conheceu os artrópodes? Onde aprendeu sobre eles?

4. Quais critérios você utilizaria para diferenciar os artrópodes uns dos outros?

5. Você acha que a disciplina de Ciências da sua escola lhe dá suporte para conhecer os artrópodes? Por quê?

6. O que você acha que deveria melhorar no ensino de ciências sobre artrópodes?

7. Como a modelagem ajudou no aprendizado sobre artrópodes?

Questionário A2 - Questionário aplicado pós-projeto aos alunos do Grupo I ( alunos do 7o Ano do Ensino Fundamental)

Carlos Henrique de Brito - Graduado em Licenciatura Plena e Bacharelado em Ciências Biológicas pela Universidade Estadual da Paraíba (2000); Mestre em Agronomia/Produção Vegetal pela Universidade Federal da Paraíba (2003) e Doutor em Agronomia/Produção Vegetal pela Universidade Federal da Paraíba (2007). Trabalhou como pesquisador na Empresa Estadual de Pesquisa Agropecuária da Paraíba/FINEP/CNPq. Atualmente é pesquisador/professor da Universidade Federal da Paraíba Campus II - Areia - PB, nos componentes curriculares Zoologia e Entomologia. Tem experiência na área de Resistência de plantas a pragas (Spodoptera frugiperda, Cochonilha-do-carmim, Extratos vegetais, Produtos alternativos, Inseticidas) bioecologia de insetos e manejo Ecológico de pragas - carlos@cca.ufpb.br

Joallyson Gonçalves Beserra - Universidade Federal da Paraíba - 